\title{
Potencial germinativo de sementes de Aroeira Myracrodruon urundeuva Fr. coletadas de população no cariri paraibano
}

\section{Germinative potential of Aroeira Myracrodruon urundeuva Fr. seeds collected in the cariri region of the paraíba state}

\author{
Raquel de Queiroz Diniz ${ }^{1}$, Belísia Lúcia Moreira Toscano Diniz ${ }^{2}$, Gilvaneide Alves de Azeredo ${ }^{2}$, Vênia Camelo de Souza ${ }^{3}$, \\ Emanuel MoreiraPereira ${ }^{4}$
}

Resumo: A aroeira (Myracrodruon urundeuva)é uma espécie pioneira que apresenta ampla distribuição geográfica, podendo ser encontrada em rios, córregos, como também em terrenos secos e pedregosos. Na comunidade vegetal no Sítio Quixaba, Taperoá, PB, não mais se observa uma quantidade grande de indivíduos como existia há anos atrás. Diante da importância que a espécie possui, este trabalho visa avaliar o potencial germinativo de sementes provenientes de oito indivíduos coletadas em uma população vegetal localizada no Sítio Quixaba no município de Taperoá.PB. O experimento foi conduzido sob condições controladas (laboratório $/ 25^{\circ} \mathrm{C}$ ) e não controladas (viveiro). Foram avaliadas as seguintes características: germinação, índice de velocidade de germinação (IVG) e tempo médio de germinação, durante um período de 30 dias. Nas condições de viveiro, após um período de 70 dias, foram avaliadas as seguintes variáveis: altura de plantas, número de folhas, diâmetro de colo, massa seca de raiz e de parte aérea. O delineamento foi inteiramente casualizado com oito tratamentos (indivíduos) e quatro repetições de 25 sementes. Houve variação na qualidade fisiológica das sementes provenientes dos indivíduos da população de aroeira localizada no Sítio Quixaba em Taperoá-PB; sugere-se que estudos fenológicos sejam desenvolvidos na população estudada e em outras existentes no Sítio Quixaba para entendimento do comportamento germinativo e de vigor das sementes.

Palavras-chaves: Aroeira, população, germinação, caatinga.

\begin{abstract}
The aroeira (Myracrodruon urundeuva) is a pioneer species with broad geographic distribution and can be found in rivers, streams, as well as in dry and rocky terrain. In plant community in Quixaba,Taperoá, PB, no longer sees a lot of individuals as it existed years ago. Given the importance that the species has, this study aims to evaluate the potential germination of seeds from eight individuals collected in a plant population located in community Quixaba in the municipality of Taperoá-PB. The experiment was conducted under controlled conditions (laboratory / $25^{\circ} \mathrm{C}$ ) and uncontrolled (nursery). The following characteristics were evaluated: germination, germination speed index (GSI) and mean germination time, over a period of 30 days. In nursery conditions, after a period of 70 days, the following variables were evaluated: plant height, leaf number, stem diameter, dry weight of root and shoot. The design was completely randomized with eight treatments (individuals) and four replicates of 25 seeds.
\end{abstract}

Key words: Aroeira, population, germination, caatinga

\footnotetext{
*Autor para correspondência

Recebido para publicação em05/02/2015; aprovado em 24/03/2015

${ }^{1}$ Graduada do Curso de Licenciatura em Ciências Agrárias UFPB VIRTUAL - Campus III /Bananeiras - PB.

2* Prof. Drs. Departamento de Agricultura/CCHSA/UFPB - E-mail: azeredogil@yahoo.com.br

${ }^{3}$ Prof. Dra. Departamento de Ciências Básicas e Sociais/CCHSA/UFPB ${ }^{4}$ Inserir aqui Titulação, Instituição, E-mail:vênia_camelo@ hotmail.com

${ }^{4}$ Pós-graduando em Engenharia Agrícola - UFCG/CTRN - Universidade Federal de Campina Grande, e-mail: emmanuel16mop@ @otmail.com
} 


\section{INTRODUÇÃO}

A Caatinga é um importante ecossistema que tem grande parte do seu patrimônio biológico com distribuição restrita ao Brasil. É rica em biodiversidade, endemismos e bastante heterogênea. Por causa da sua degradação, a produção de sementes e mudas de espécies nativas com vistas ao reflorestamento e à recuperação de áreas degradadas da Caatinga é de suma importância (Workshop de Sementes e Mudas da Caatinga, 2014).

A aroeira-do-sertão (Myracrodruon urundeuva Fr. All) é uma Anacardiaceae que possui ampla distribuição geográfica, podendo ser encontrada no México, Argentina, Bolívia e Paraguai. É originária do Brasil, ocorrendo desde a Caatinga até a Floresta Pluvial Tropical, passando por formações do Cerrado (FREITAS et al., 2007). O porte da aroeira varia conforme a região de sua ocorrência (LORENZI 1992; ANDRADE et al. 2000), podendo atingir $30 \mathrm{~m}$ de altura (RIZZINI 1971). Geralmente, a espécie floresce entre julho e setembro e a maturação dos frutos ocorre de setembro a outubro (LORENZI 1992; ANDRADE et al. 2000).

Em decorrência desses múltiplos usos, a aroeira vem sofrendo um processo de exploração intensa, de forma predatória, causando a devastação de suas populações naturais. Além disso, deve-se salientar que a exploração seletiva da aroeira para uso na indústria madeireira praticamente extinguiu os indivíduos de grande porte (BRANDÃO 2000), sendo, portanto, considerada ameaçada de extinção e categorizada como vulnerável (MENDONÇA e LINS 2000). Assim, estudos ecológicos básicos, principalmente relacionados com a germinação das sementes de $M$. urundeuva, são essenciais para que possam gerar informações que venham subsidiar programas de preservação, manejo e restauração de suas populações.

Diante das razões apresentadas e da necessidade de se preservar a aroeira, pela sua importância ecológica para o Cariri Paraibano, este trabalho teve como objetivo avaliar o potencial germinativo de sementes de $M$. urundeuva coletada sem uma população sob condições de viveiro e de laboratório

\section{MATERIAL E MÉTODOS}

As sementes foram coletadas de oito indivíduos provenientes de uma população de plantas localizadas na vegetação da Caatinga, município de Taperoá, Paraíba (Figura 1), utilizando-se, como critério de seleção, a presença de material reprodutivo: frutos e sementes. No entanto, os indivíduos foram selecionados de forma aleatória bem como pela facilidade de acesso. Na comunidade vegetal, havia plantas nativas, a exemplo do marmeleiro, jurema, mandacaru, como pode ser visualizado na Figura 2.

O município está localizado a $7^{\circ} 12^{\prime \prime} 23^{\prime \prime}$ Sul - $36^{\circ} 49^{\prime \prime}$ 25 " Oeste, na microrregião do Cariri Ocidental. De acordo com o IBGE (2002), Taperoá, com uma área territorial de 640 $\mathrm{km}^{2}$, está incluída na área geográfica de abrangência do semiárido brasileiro, definida pelo Ministério da Integração Nacional em 2005. Esta delimitação tem como critérios o índice pluviométrico, o índice de aridez e o risco de seca.
Figura 1. Localização do município de Taperoá, PB.

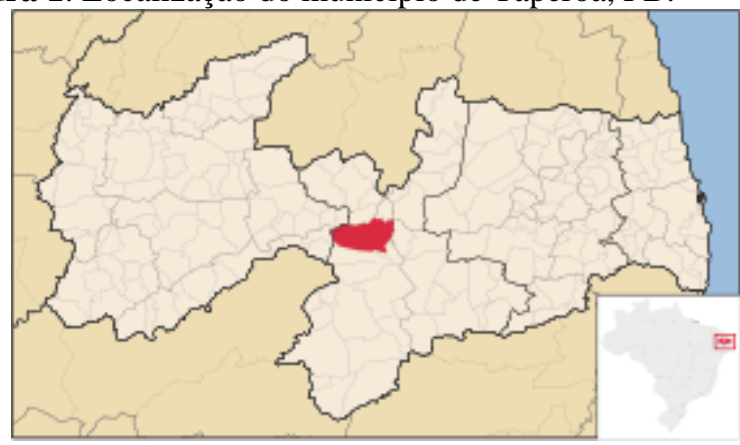

Figura 2. Área da Caatinga no município de Taperoá com um dos indivíduos de aroeira em frutificação (presença de cactáceas ao redor).

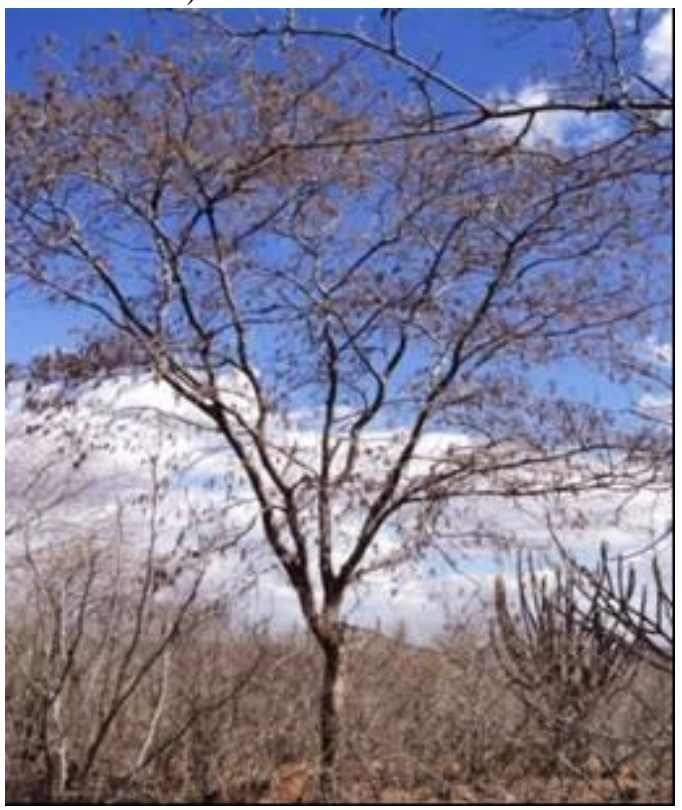

O ensaio da germinação foi conduzido no Viveiro de Produção de Mudas e no Laboratório de Tecnologia de Sementes do Centro de Ciências Humanas, Sociais e Agrárias, UFPB no Campus de Bananeiras, PB.

$O$ teste de germinação e de emergência foram conduzidos em laboratório e em viveiro, respectivamente. Inicialmente, foi efetuada a determinação do teor de água em estufa regulada a $105^{\circ} \mathrm{C}$. Após um período de 24 horas, foi feita a pesagem em balança analítica, com precisão de quatro casas decimais. O teor de água das sementes foi efetuado de acordo com Brasil (2009).

Sob condições de laboratório, o teste de germinação foi conduzido a $25^{\circ} \mathrm{C}$. O substrato utilizado foi o papel germitest, umedecido com a quantidade de três vezes o peso do papel. Foram utilizadas quatro repetições de 25 sementes para cada indivíduo. O ensaio teve uma duração de 30 dias. A germinação ocorreu aos quatro dias após a semeadura e considerou-se como critério de germinação o surgimento da raiz primária. As variáveis analisadas foram: percentagem de germinação, índice de velocidade de germinação e tempo médio de germinação.

No viveiro de produção de mudas do CCHSA foi conduzido também um ensaio de emergência. Neste caso, o substrato utilizado foi a areia lavada, em bandejas, com quatro repetições de 25 sementes para cada tratamento. A duração do ensaio foi de 70 dias. O critério adotado para a 
emergência das plântulas foi o surgimento do hipocótilo sobre o substrato. Durante esse período, foram avaliadas as seguintes características: percentagem de emergência, índice de velocidade de emergência, tempo médio de emergência, altura de plantas, número de folhas, diâmetro de colo, massa seca de raiz e massa seca de parte aérea.

O delineamento estatístico utilizado foi inteiramente casualizado com oito tratamentos (indivíduos) e quatro repetições. As médias foram comparadas pelo Teste de Tukey a 5\% de probabilidade. O programa estatístico utilizado foi o STAT, Sistema de Análises Estatísticas, Versão 2.0/Jaboticabal.

\section{RESULTADOS E DISCUSSÃO}

Os teores de água para os indivíduos 1, 2, 3, 4, 5, 6, 7 e 8 variaram de 18 a $23 \%$. Estes foram considerados elevados, tendo em vista que o ensaio foi conduzido imediatamente após a coleta das sementes. Quando elevado, o teor de água pode favorecer o desempenho de sementes nos testes de germinação (AMARO et al. 2014). Em laboratório, as sementes mais úmidas, dentro de certos limites, germinam mais rapidamente (MARCOS FILHO 1999).

A germinação de sementes de aroeira, sob condições de laboratório (Figura 3A), foi elevada nos indivíduos 6, 2, 1 e 3, diferindo estatisticamente dos demais. Em condições de viveiro (Figura 3B), os indivíduos 6, 2 e 1 apresentaram comportamento idêntico, atingindo os maiores valores de emergência. Os indivíduos 5, 7 e 8, em ambas as condições, foram aqueles que tiveram desempenho inferior, não demonstrando serem indivíduos produtores de sementes com qualidade elevada.

Quanto ao índice de velocidade de germinação e de emergência (Figuras 4A, 4B), em ambas as condições de semeadura, os indivíduos 6,2 e 1 continuaram se sobressaindo, indicando que as sementes provenientes desses indivíduos eram de qualidade superior, ao contrário dos 5, 7 e 8 , que evidenciavam qualidade inferior. Aparentemente, os indivíduos 6, 2 e 1 que obtiveram desempenho superior em relação aos outros no tocante a estas variáveis, tinham características similares em relação a altura, conformação de tronco, copa, frutificação. Já o indivíduo 7, por exemplo, cujas sementes, foram de baixa qualidade, estava localizado em meio a pedregulhos e apresentava galhos pequenos e finos, porém, com os primeiros cachos já brotados e com sementes . Dentre todos os indivíduos, este foi o que possuía o menor número de sementes em sua copa. Possivelmente, pela localização da árvore em meio a pedras e pela presença de caprinos e ovinos na área, a possibilidade de predação, pode ser um indicativo da baixa qualidade fisiológica das sementes provenientes deste indivíduo.

Dentro de uma mesma espécie florestal podem existir variações individuais entre árvores devido às influências ambientais durante o desenvolvimento das sementes e à variabilidade genética. Estes fatores têm sido apontados como as grandes causas da variação no processo germinativo (SANTOS 2007).Lima et al. (2014), por exemplo, encontraram variações na qualidade fisiológica das sementes de Poincianel lapyramidalis (Tul.) L.P. Queiroz (Fabaceae) provenientes de várias árvores e de uma única área de coleta.

Um dos critérios a serem considerados para a escolha de árvores matrizes é que esta tem que estar livre de pragas e doenças (SENA e GARIGLIO 2008). Além da escolha adequada dos indivíduos e da área, outro ponto importante no processo é a época de colheita. Esta deve ser realizada quando as sementes atingem a maturação fisiológica, visto que nesta época elas apresentam maior porcentagem de germinação, maior vigor e maior potencial de armazenamento (NOGUEIRA e MEDEIROS 2007).

É importante destacar neste trabalho que as sementes foram coletadas no chão, na área de projeção da copa, na mesma época, para todos os indivíduos. Apesar de não terem sido investigadas as características físicas de cada indivíduo, vale ressaltar que a maioria dos indivíduos apresentava visualmente características semelhantes quanto a copa, altura, produção de frutos e sementes. E todos eles tinham sementes abaixo de sua copa, o que dá indícios de que as sementes já tinham atingido a maturidade fisiológica.

Em relação ao tempo médio de germinação (Figuras $5 \mathrm{~A}$ e 5B), independentemente de onde foi conduzido o ensaio, as sementes provenientes de todos os indivíduos, com exceção do 5 e do 7, germinaram em torno de 4 dias. Ou seja, mesmo que alguns indivíduos tenham se sobressaído em termos de velocidade e porcentagem de germinação, o tempo médio requerido para que as sementes germinassem foi o mesmo para praticamente todos os indivíduos.

Figura 3. Germinação de sementes de aroeira provenientes de oito indivíduos sob condiçõesde laboratório (A) e viveiro (B).

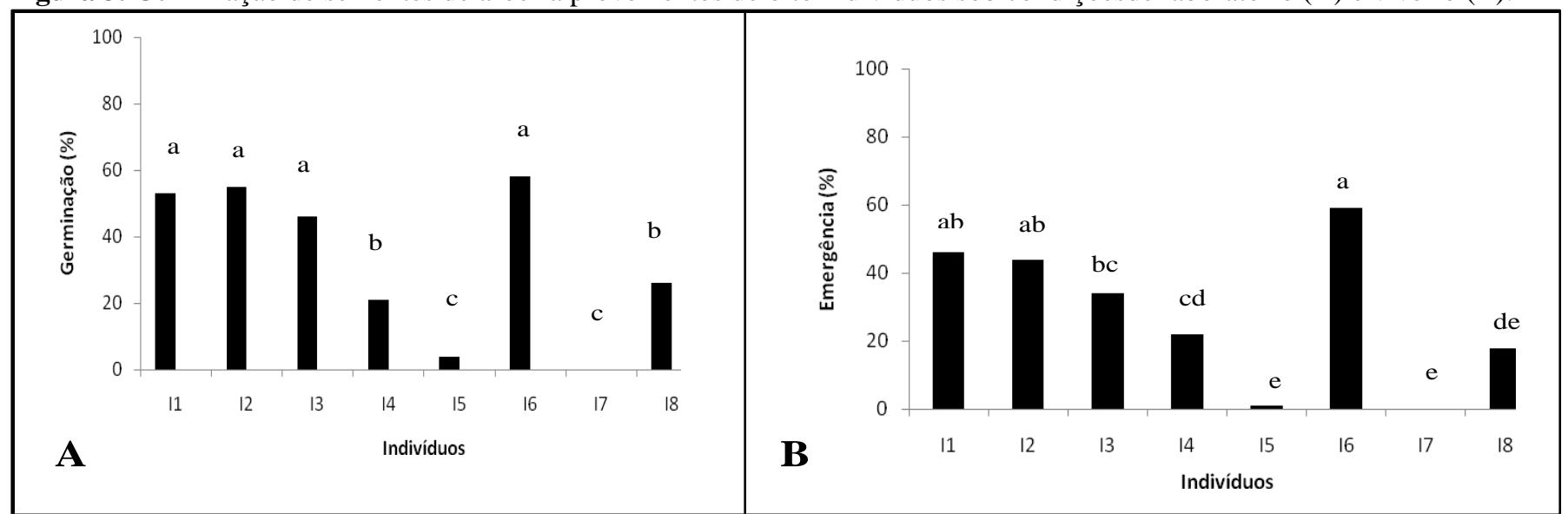


Figura 4. Índice de velocidade de germinação (IVG) de sementes de aroeira provenientes de oito indivíduos sob condições de laboratório (A) e viveiro (B).

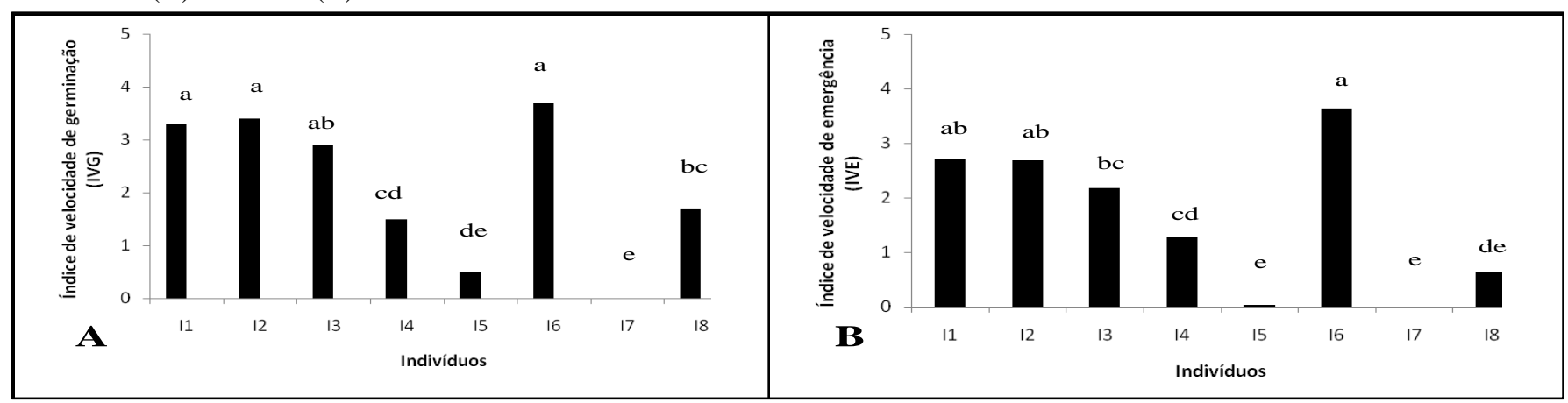

Figura 5. Tempo médio de germinação de sementes de aroeira provenientes de oito indivíduos sob condições de laboratório (A) e viveiro (B).

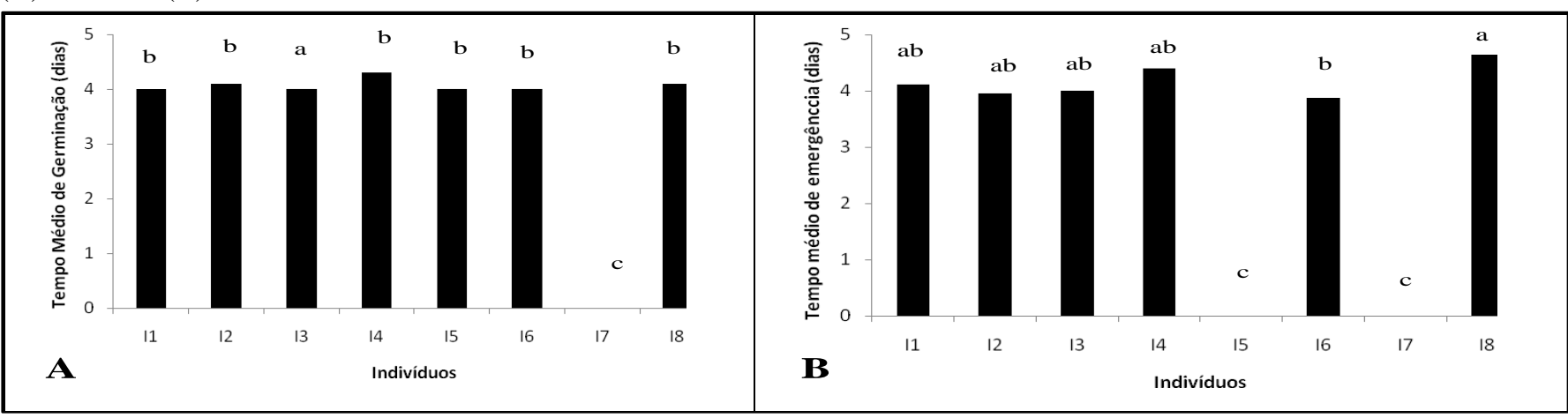

Os dados de altura, número de folhas, diâmetro de colo e massa seca de raiz e de parte aérea foram referentes apenas ao ensaio conduzido em viveiro e tais dados foram obtidos aos 70 dias após a semeadura. Observou-se na Figura 6 que o indivíduo 8 foi a que mais cresceu em relação às demais, não diferindo dos indivíduos 2, 3 e 6 .

Figura 6. Altura $(\mathrm{cm})$ de plântulas de aroeira provenientes de oito indivíduos sob condições de viveiro.

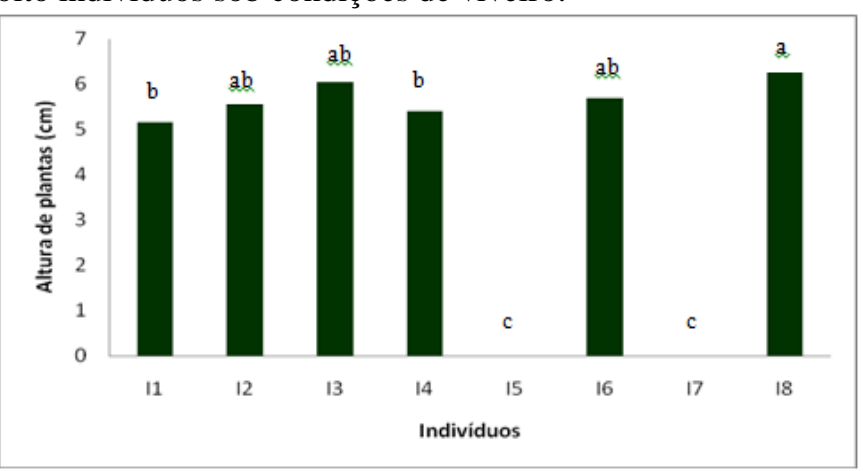

A altura da parte aérea pode ser utilizada como uma estimativa da predição do crescimento inicial no campo, apesar de que essa característica pode ser facilmente influenciada por algumas práticas de manejo adotadas nos viveiros, entretanto, recomenda-se a análise combinada com outras características tais como: diâmetro do coleto, relação peso das raízes/peso da parte aérea (GOMES et al. 2002).

Segundo Gomes e Paiva (2004), o diâmetro de colo é facilmente mensurável, sendo considerado por muitos pesquisadores como uma das mais importantes características para estimar a sobrevivência de mudas de espécies florestais no campo. De acordo com estes autores, o padrão de qualidade de mudas de várias espécies florestais, prontas para o plantio, possui alta correlação com esse parâmetro e isso pode ser observado nos significativos aumentos das taxas de sobrevivência e do crescimento das plantas no campo.

Quanto ao número de folhas (Figura 7) o indivíduo 1 apresentou maior número de folhas, não diferindo dos indivíduos 3, 4, 6 e 8. Quanto ao diâmetro de colo (Figura 8), os indivíduos 1, 2 e 3 se sobressaíram com maiores valores de diâmetro, porém, não diferiram estatisticamente dos indivíduos 6 e 8 . O diâmetro do coleto tomado isoladamente ou combinado com a altura, é umas das melhores características morfológicas para predizer a qualidade das mudas de espécies florestais (GOMES et al. 2002). O maior diâmetro sugere maior particionamento de fotoassimilados da parte aérea (SCALON et al. 2001), portanto, é uma característica desejável quando se pensa em produção de mudas.

Figura 7. Número de folhas de plântulas de aroeira provenientes de oito indivíduos sob condições de viveiro.

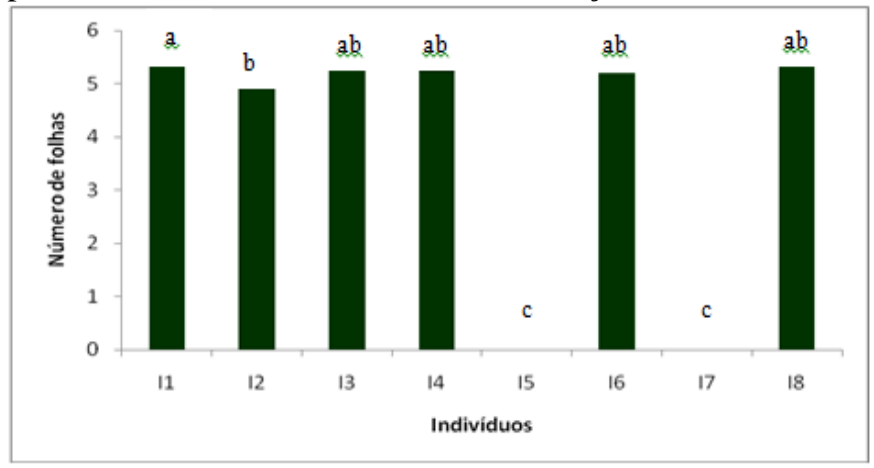

Figura 8. Diâmetro de colo $(\mathrm{mm})$ de plântulas de aroeira provenientes de oito indivíduos sob condições de viveiro. 


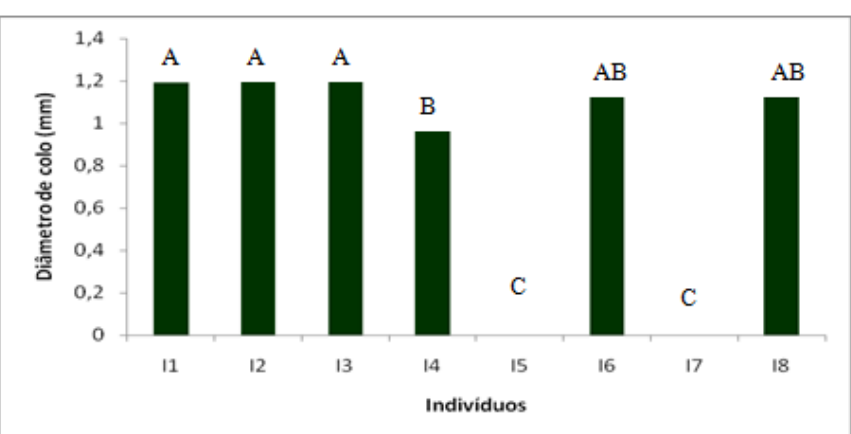

Além de maior porcentagem de emergência das plântulas, determinadas progênies podem expressar maior velocidade de crescimento em altura e diâmetro do colo, que conferem à plântula maior capacidade de competição, ocupação e aproveitamento do ambiente em condições naturais, o que favorece o estabelecimento e sobrevivência dessas populações (Martins-Corder e Saldanha 2006). Assim, em trabalho realizado por Andrade et al. (1996), constatou-se que as plântulas de palmeira juçara (Euterpe edulis Martius) com maior crescimento inicial foram capazes de aproveitar melhor as reservas hídricas do solo, permitindo um rápido estabelecimento.

Os indivíduos 2 e 6 , em relação a massa seca de raiz (Figura 9), obtiveram valores mais elevados, no entanto, foram iguais estatisticamente ao 3. Quanto a massa seca da parte aérea (Figura 10), os indivíduos 2 e 8, apesar de terem apresentado melhor desempenho não diferiram dos 3 e 6 .

Em relação a estas variáveis, Santos (2004) considerou que a matéria seca de plântulas não se mostrou eficiente na discriminação de lotes de sementes de sementes de Sebastiania commersoniana.

Percebe-se claramente, considerando as características avaliadas neste trabalho, variação entre os indivíduos. De acordo com Turnbull (1975), dentro de uma mesma espécie, existem variações individuais devido às influências do ambiente durante o desenvolvimento das sementes e da variabilidade genética, o que pode se refletir sobre o comportamento germinativo e no desenvolvimento das plântulas.

Figura 9. Massa seca de raiz (mg) de plântulas de aroeira provenientes de oito indivíduos sob condições de viveiro.

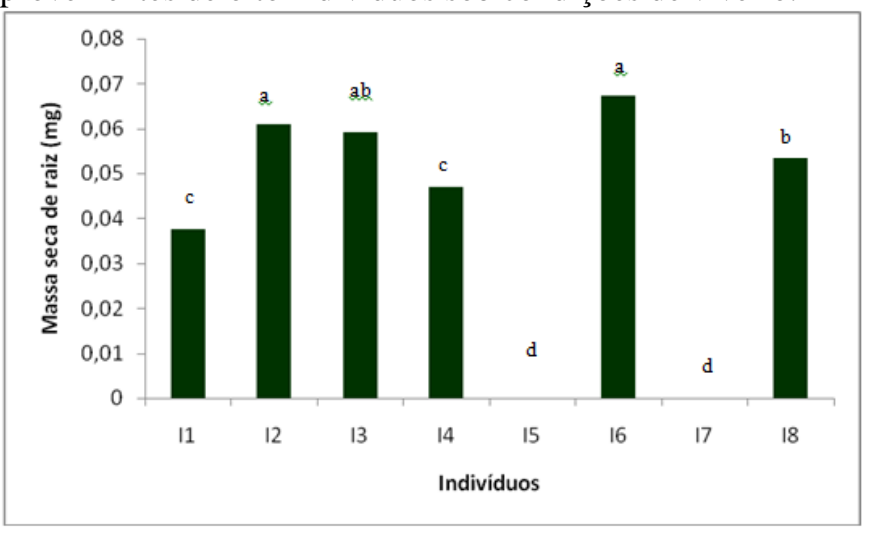

Figura 10. Massa seca de parte aérea (mg) de plântulas de aroeira provenientes de oito indivíduos sob condições de viveiro.

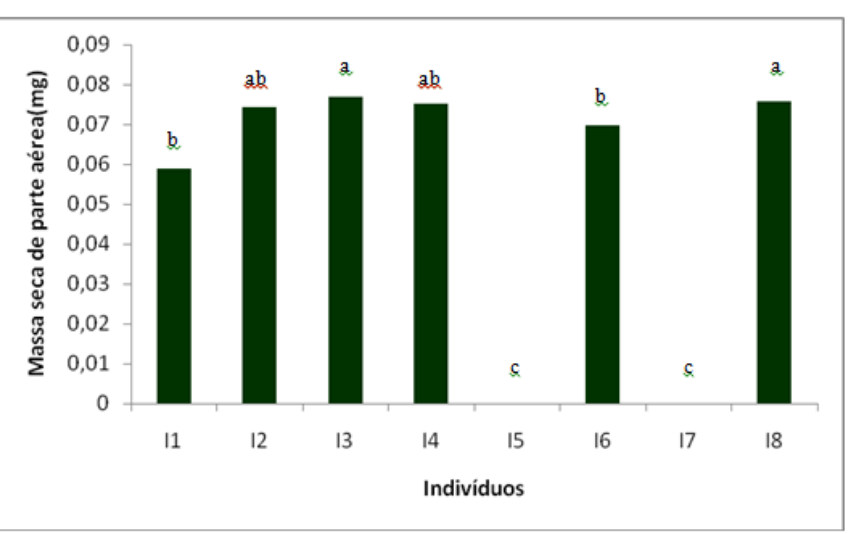

A massa seca, segundo Rosa et al. (2009), é um parâmetro morfológico importante quando se pensa na produção de mudas, pois com maior biomassa, a muda apresenta maior resistência às condições adversas do campo, promovendo maior sobrevivência, minimizando gastos com replantios (GOMES e PAIVA 2004).

Pode-se perceber, em função dos resultados alcançados que, dependendo da variável analisada, um determinado indivíduo ou indivíduos se sobressaíram em detrimento de outros, não se observando um comportamento similar para todas as variáveis. Mesmo assim, pode-se inferir, pelos dados apresentados que, dentre os indivíduos estudados, os de número 2, 3, 6 e 8 foram aqueles que se destacaram, considerando a maioria das características avaliadas, enquanto que os indivíduos 5,7 e 4 foram os que tiveram desempenho inferior.

Os resultados indicaram que as sementes provenientes destes indivíduos, mesmo tendo sido coletadas na mesma região e no mesmo período, expressaram comportamentos distintos, mostrando possivelmente que o ambiente (clima, tipo de solo, disponibilidade hídrica e nutricional,) e ou tamanho, idade, variabilidade genética dos indivíduos afetaram a qualidade das sementes produzidas, mediante as variáveis analisadas neste trabalho.

\section{CONCLUSÕES}

Houve variação na qualidade fisiológica das sementes provenientes dos indivíduos da população de aroeira localizada no Sítio Quixaba em Taperoá-PB;

Sugere-se que estudos fenológicos sejam desenvolvidos na população estudada e em outras existentes no Sítio Quixaba para entendimento do comportamento germinativo e de vigor das sementes.

\section{REFERÊNCIAS BIBLIOGRÁFICAS}

ALMEIDA S.P de.; PROENÇA C.E.B, SANO S.M, RIBEIRO J.F. Cerrado: espécies vegetais úteis. Planaltina: Embrapa-CPAC. 188p.1998.

AMARO, H.T.R.; DAVID, A.M.S. de S.; SILVA NETA, I.C; ASSIS, M. de .O.; ARAÚJO, E.F; ARAÚJO, R.F. Teste de envelhecimento acelerado em sementes de crambe (CrambeabyssinicaHochst), cultivar FMS Brilhante. Revista Ceres, Viçosa, v.61, n.2, p.202-208.2014.

ANDRADE ACS, VENTURI S, PAULILO MT. Efeito do tamanho das sementes de Euterpe edulis sobre a 
emergência e crescimento inicial. Revista Brasileira de Sementes, 18 (2):.225-231.1996.

ANDRADE MW de, LUZ JMQ, LACERDA AS, MELO PRA. Micropropagação da aroeira (Myracrodruomurundeuva Fr. All). Ciência a Agrotecnologia, 24 (1):174-180.2000.

BERTONI JE de A, DICKFELDT EP. Plantio de Myracrodruonurundeuva fr. all. (aroeira) em área alterada de floresta: desenvolvimento das mudas e restauração florestal. Revista do Instituto Florestal, São Paulo, 19 (1): 31-38.2007.

BRANDÃO M. Caatinga. In: MENDONÇA MP, LINS LV. (Orgs). Lista vermelha das espécies ameaçadas de extinção da flora de Minas Gerais. Belo Horizonte: Fundação Biodiversitas e Fundação Zôo-Botânica de Belo Horizonte, p.75-85.2000.

GOMES JM, COUTO L, LEITE HG, XAVIER A, GARCIA SLR. Parâmetros morfológicos na avaliação da qualidade de mudas de Eucalyptusgrandis. Revista Árvore, 26 (6): 655-664.2002.

GOMES JM, PAIVA HN. Viveiros florestais. 3. ed. Viçosa: UFV, 2004, 116p. 2004.

LIMA CF, BRUNO, R de LA, SILVA $K$ da RG da S, PACHECO MV, ALVES EU da S. Qualidade fisiológica de sementes de diferentes árvores matrizes de Poincianellapyramidalis (Tul.) L. Revista Ciência Agronômica, 45 (2): 370-378.2014.

LORENZI H. Árvores brasileiras: manual de identificação e cultivo de plantas arbóreas nativas do Brasil. São Paulo: Plantarum, 1: 368p.1992.

MARCOS FILHO J. Teste de envelhecimento acelerado. In: KRZYZANOWSKI FC, VIEIRA RD, FRANÇA NETO JB. Vigor de sementes: conceitos e testes. Londrina: Abrates, cap.3. p.3.21. 3.24.1999.

MARTINS-CORDER, MP, SALDANHA CW. Germinação de sementes e crescimento de plântulas de diferentes progênies de Euterpe edulis Mart. Revista Árvore, 30 (5): 693-699. 2006.

MELO JÚNIOR AF, CARVALHO D, POVOA JRS, BEARZOTI E. Estrutura Genética em populações Naturais de Pequizeiro (Caryocar brasilienseCamb.). ScientiaFlorestalis, Ribeirão Preto, 66: p. 56-65.2004.

MENDONÇA MP, LINS LV. (Orgs.). Lista vermelha das espécies ameaçadas de extinção da flora de Minas Gerais. Belo Horizonte: Fundação Biodiversitas. 157 p. 2000.

NOGUEIRA AC, MEDEIROS AC de S. Extração e beneficiamento de sementes florestais nativas. Circular Técnica, Colombo: Embrapa Florestas, 131:7p.2007.

QUEIROZ, J.E. Avaliação e monitoramento da salinidade do solo. In: GHEYI H R; DIAS N S; LACERDA C F. Manejo da salinidade na agricultura: estudos básicos e aplicados. Fortaleza, INCT Sal, 2010.

RIZZINI CT. Árvores e madeiras úteis do Brasil: Manual de Trologia Brasileira, São Paulo: Edgar Blücher.1971.
ROGALSKI JM, BERKENBROCK IS, REIS A, REIS MS. Sucessão e diversidade como fundamentos básicos na restauração ambiental. In: Simpósio Nacional e Congresso Latino-americano de Recuperação de Áreas Degradadas - SOBRADE, 4., Anais... Curitiba. p. 433439.2005 .

SANTOS FS. Biometria, germinação e qualidade fisiológica de sementes de Tabebuia chrysotricha (Mart. Ex A. Dc.) Standl. provenientes de diferentes matrizes (Dissertação de Mestrado), Jaboticabal, 48 f.2007.

SANTOS SRG. Qualidade fisiológica e armazenamento de sementes de Sebastianiacommersoniana (Baill.)Smith\&Downs. 2004. 95f. Tese (Doutorado em Produção Vegetal). Jaboticabal.2004.

SCALON S de PQ, SCALON FILHO H, RIGONI MR, VERALDO F. Germinação e crescimento de mudas de pitangueira (Eugenia uniflora L.) sob condições de sombreamento. Revista Brasileira de Fruticultura, Jaboticabal, 3 (3):652-655.2001.

SENA CM de, GARIGLIO MA. Sementes florestais: colheita, beneficiamento e armazenamento. Natal: MMA/ Secretaria de Biodiversidade e Florestas/Departamento de Florestas/Programa Nacional de Florestas/Unidade de Apoio ao PNF no Nordeste, 28p. 2008.

SILVA, Í. N.; FONTES, L. O.;TAVELLA, L. B.; et al. Qualidade de água na irrigação.Agropecuária Científica no Semiárido, v.07, n 03 julho/setembro 2011 p. 01 - 15 . 2011.

TURNBULL JW. Seed extraction and cleaning. In: REPORT ON THE AO/DANIDA TRAINING COURSE ON FOREST SEED COLLECTION AND HANDLING, Chiang mai. ProceedingsRome: FAO, p.135-151.1975.

VIANA, GSB, MATOS FJA, BANDEIRA MAM, RAO VS. Aroeira-do-sertão: estudo botânico, farmacognóstico, químico e farmacológico. Fortaleza: Universidade Federal do Ceará, 164p.1995.

VON SPERLING, MARCOS /Introdução a qualidade das águas e ao tratamento de esgotos/ Marcos Von Sperling. - 3. Ed. - Belo Horizonte: Departamento de Engenharia Sanitária e Ambiental; Universidade Federal de Minas Gerais; 2005.

WORKSHOP DE SEMENTES E MUDAS DA CAATINGA.4, Anais.... Petrolina: Embrapa Semiárido, 145 p. (Embrapa Semiárido. Documentos, 258).2014.

YAMAMOTO MA, SILVA FILHO D F. Determinação de árvores matrizes na floresta urbana por um banco de dados relacional. In: Congresso Brasileiro de Arborização Urbana, 8., Anais... São Paulo.2004.

ZAIDAN LBP, BARBEDO CJ. Quebra de dormência em sementes. In: FERREIRA AG, BORGHETTI F. (Orgs). Germinação: do básico ao aplicado. Porto Alegre: Artmed, p.135-146.2004. 